\title{
Pengaruh Eksitasi Gelombang Iradiasi Ultrasonik Terhadap Kadar Tanin pada Maserasi Biji Pinang Wangi
}

\author{
Rosalina ${ }^{1}$, Ferry Ikhsandy ${ }^{2}$, Agung Kurnia Yahya ${ }^{2}$ Hibrah $^{2}$ \\ ${ }^{1}$ Prodi Teknologi Rekayasa Bioproses Energi Terbarukan, Politeknik ATI Padang, Jl. Bungo Pasang-Tabing, Padang, 25171, Indonesia \\ ${ }^{2}$ Prodi Teknik Kimia Bahan Nabati, Politeknik ATI Padang, Jl. Bungo Pasang-Tabing, Padang, 25171, Indonesia
}

\section{ARTICLE INFORMATION}

Received: November 11, 2021

Revised: December 27, 2021

Available online: December 29, 2021

\section{KEYWORDS}

Areca nut, Maceration, Tannins, Ultrasonic Irradiation Wave

\section{CORRESPONDENCE}

Name: Rosalina

E-mail: rosalina@poltekatipdg.ac.id

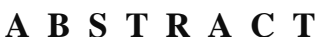

Nagari Sikucua, Kampung Dalam Subdistrict, Padang Pariaman produces nearly 800 tons of fragrant areca nut every year which is sent to Jambi to meet export needs. Areca nut contains tannins, substances that have many benefits, some of which are anti-inflammatory, corrosion inhibitors, antioxidants. This study aims to obtain tannins in areca nut extract through a kinetic maceration process with pre-treatment with ultrasonic irradiation wave. The dried areca nut was ground and sieved with various sizes of 20,40 and 70 mesh and then extracted with ethanol as solvent. The concentration of ethanol used consisted of $35 \%, 50 \%$, $65 \%$ and $80 \%$. Ultrasonic irradiation waves were given for the initial 15 minutes of maceration and then continued with kinetic maceration for up to 4 hours in a water bath at $45^{\circ} \mathrm{C}$. The extraction results were concentrated in a rotary evaporator and then tested for tannin levels using Follin Denish reagent in the standard series of tannic acid as a comparison with spectrophotometer UV-Vis. The highest yield of tannin content $11.10 \%$ was obtained in the 4-hour maceration process with pre-treatment ultrasonic irradiation at concentration of $80 \%$ ethanol with a size of 40 mesh.

\section{PENDAHULUAN}

Pinang merupakan tanaman monokotil sebagai bagian dari famili Palma. Memiliki batang lurus dengan tinggi bisa mencapai 20 meter. Normalnya setiap pinang dewasa memiliki 7-12 helai daun. Setiap tangkainya dapat terdiri dari 100-250 buah pinang. Habitat asli pohon pinang dapat ditemukan di daerah Kalimantan, Jawa dan Sumatera. Lebih dari 100 varietas pinang yang tumbuh di Indonesia, di wilayah Sumatera ada varietas areca catechu, areca trianda, areca latiloba. Di Sumatera Barat sendiri terdapat jenis pinang wangi yang merupakan bibit pinang unggul lokal yang menjadi salah satu Blok Penghasil Tinggi (BPT) di Nagari Sikucua Kecamatan Kampung Dalam, Kabupaten Padang Pariaman. Pinang wangi memiliki aroma pandan pada kulit buah dan bijinya, namun memiliki bentuk buah yang sedikit lebih kecil dibandingkan dengan varietas pinang lainnya seperti pinang betara namun dengan warna kulit yang lebih kuning.
Masyarakat di Indonesia telah lama mengenal biji pinang untuk menyirih dan untuk keperluan pengobatan sederhana seperti obat diare, sakit gigi, obat cacingan serta sebagai pewarna tekstil. Biji pinang mengandung senyawa alkaloid seperti arecoline, areacine, areacolidine, giradiasi ultrasonikacine, iso-giradiasi ultrasonikacine, giradiasi ultrasonikacoline, dan choline, serta tannin [1].

Penelitian ini ditujukan untuk mempelajari pengaruh iradiasi gelombang ultrasonik terhadap kadar tanin dalam variasi konsentrasi pelarut dan ukuran serbuk biji pinang. Diharapkan penggunaan iradiasi gelombang ultrasonik dengan komposisi yang tepat dapat menghasilkan tanin ekstrak biji pinang dengan lebih cepat dan lebih baik.

\section{Ektraksi Padat-Cair}

Merupakan pemisahan zat terlarut dari suatu padatan dengan menggunakan pelarut. Perpindahan massa terjadi melalui proses difusi. Pada saat bahan padatan dan pelarut kontak maka solut yang konsentrasinya lebih 
tinggi didalam padatan akan berdifusi ke pelarut yang ada disekitarnya, dalam pori-pori lalu selanjutnya keluar dari padatan menuju pelarut keseluruhan (bulk solvent). Ektraksi umumnya digunakan untuk memisahkan solut dari larutan organik yang sensitif terhadap perlakuan panas atau yang memiliki beda titik didih atau leleh yang berdekatan satu sama lain. Beberapa faktor yang dapat mempengaruhi laju proses ektraksi secara umum antara lain:

\section{Ukuran Partikel Padatan}

Semakin kecil ukuran partikel maka semakin besar luas permukaan spesifik. Luas permukaan yang besar akan memperbesar laju difusi solut ke pelarut. Namun ukuran partikel yang terlalu kecil juga bisa memperlambat difusi dikarenakan pori-pori padatan tertutup dan juga akan mempersulit pemisahan ekstrak dan rafinatnya.

\section{Pelarut}

Sifat pelarut yang digunakan disesuaikan dengan jenis solut yang akan diekstrak sehingga selektifitasnya tinggi. Pelarut tidak beracun ataupun mudah terbakar serta stabil namun inert.

3. Temperatur

Semakin tinggi temperatur maka molekul-molekul akan bergerak dengan lebih cepat sehingga akan mempercepat terjadi tumbukan sehingga memudahkan terjadinya proses difusi. Namun memproses bahan organik pada temperatur tinggi dapat membawa dampak kerusakan bahan.

4. Pengadukan

Pengadukan akan mempercepat laju transfer massa dari permukaan padatan (solid) menuju pelarut keseluruhan dan mencegah pengendapan.

\section{Gelombang Ultrasonik}

Gelombang ultrasonik merupakan gelombang bunyi dengan frekuensi diatas $20 \mathrm{KHz}$ sampai dengan $1 \mathrm{GHz}$ adapun gelombang bunyi dengan frekuensi diatas $1 \mathrm{GHz}$ telah masuk area Hipersonik. Sebagai gelombang suara, gelombang ultrasonik mampu merambat melalui media padat, cair dan gas yang memiliki sifat yang elastis [2].

Gelombang ultrasonik dapat dengan mudah menembus bahan buram dimana gelombang optik tidak bisa melakukannya. Dikarenakan karakteristik seperti inilah gelombang iradiasi ultrasonik banyak diaplikasikan dalam banyak hal seperti bidang komunikasi dan kesehatan serta berbagai industri lainnya.

Aplikasi gelombang akustik frekuensi rendah dimulai dari transduser piezoelektrik, resonator kuarsa, neraca mikro kuarsa hingga pada alat-alat penginderaan seperti penginderaan aliran, level dan jarak yang banyak digunakan dalam pengukur jarak, pembuka pintu garasi, kamera pengintai dll. Sedangkan gelombang ultrasonik frekuensi tinggi banyak diaplikasikan dalam pekerjaan berat seperti di industri pengeboran, pemotongan, dan pembersih ultrasonik. Iradiasi ultrasonik berdaya tinggi juga berguna menyuplai sejumlah panas, dalam penyolderan ultrasonik dan pengelasan logam dan plastik [3].

Dalam medium cair, gelombang iradiasi ultrasonik akan memberikan efek kavitasi akustik terhadap larutan yang dilaluinya. saat larutan mengalami regangan, gelombang akan mampu memecah ikatan molekul antar larutan selanjutnya gas-gas yang terbentuk akan terperangkap saat larutan mengalami rapatan. Efek kavitasi ditunjukkan pada gambar 1 [4].
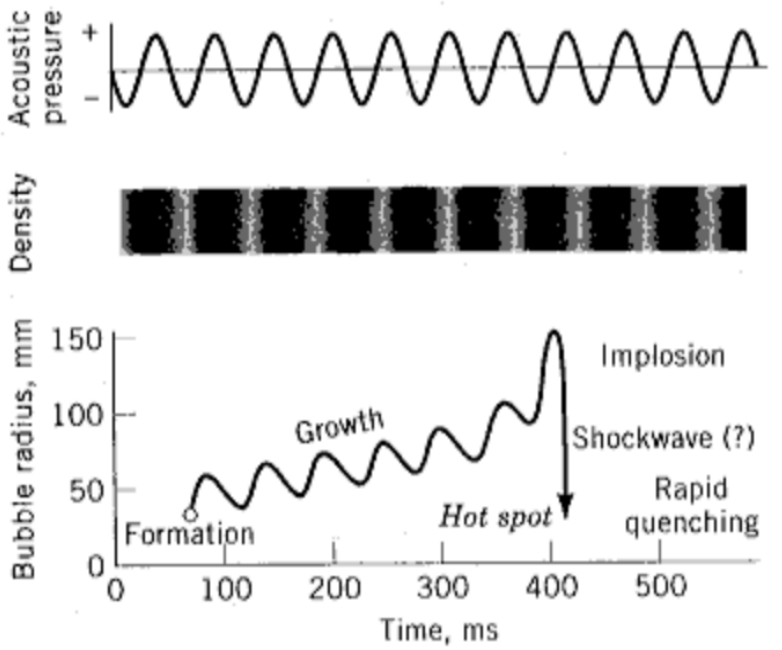

Gambar 1. Kavitasi Akustik Transien: Asal sonokimia dan sonoluminescence [4]

Berdasarkan frekuensinya gelombang iradiasi ultrasonik termasuk kedalam jenis gelombang mekanik longitudinal atau disebut juga (compressional waves atau $P$-waves). Gelombang jenis ini memiliki karakteristiknya kecepatan rambat yang paling cepat dengan amplitudo yang paling kecil diantara jenis gelombang lainnya. Gelombang ini dikatakan sebagai gelombang elastis karena tergantung pada keelastisan bahan yang dilaluinya. Untuk medium padat elastis homogen, kecepatan $P$-waves berbanding terbalik dengan kerapatan bahan. Semakin rapat bahan maka kecepatan akan menurun [5].

\section{Tanin}

Tanin merupakan senyawa polifenol hasil kondensasi metabolit sekunder dari fenolik sederhana. Berdasarkan kompleksitas struktur kimianya, tanin dapat dibedakan menjadi dua golongan yaitu tanin hidrolisa dan tanin non hidrolisa (tanin terkondensasi). Tanin non hidrolisa adalah tanin yang terbentuk dari biosintesis flavin dan katekin. Tanin dapat digunakan sebagai anti mikroba, anti inflamasi, anti migren [6], mampu meningkatkan 
daya ingat [7], sebagai pewarna pakaian dan perekat kayu lapis [8].

Kumpulan gugus hidroksil pada tanin memungkinkannya menjadi agen antioksidan yang kuat. Tanin tidak kompatibel dengan jenis gelatin, alkaloid, glikosida, logam-logam berat, asam lemah, garam-garam logam dan seng sulfat. Tanin akan membentuk senyawa kompleks yang tidak larut dan mengendap dalam larutannya. Kemampuan reduksi tanin mampu membentuk ion-ion logam yang kemudian membentuk senyawa komplek dengan tanin. Senyawa kompleks ini menjadi suatu lapisan pasif yang mampu mencegah akses zat korosif ke logam sehingga disebut inhibitor korosi. Aplikasi tanin sebagai green corrosion inhibitor telah diuji pada baja karbon dalam larutan HCL 3M [8].

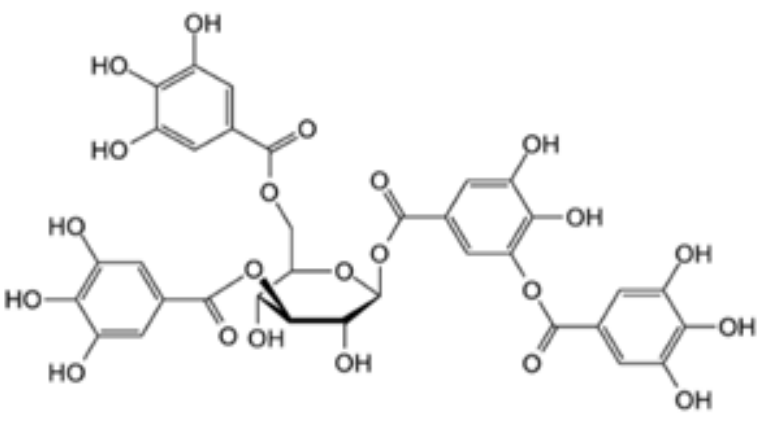

Gambar 2. Struktur Kimia Tanin

Beberapa penelitian yang telah dikembangkan dari ekstraksi tanin serta aplikasi gelombang ultrasonik pada proses ekstraksi antara lain sebagai berikut:

1. Ektraksi-distilasi limbah biji pinang menggunakan pelarut aseton $70 \%$ dan suhu ekstraksi $40^{\circ} \mathrm{C}$ didapatkan kadar tanin tertinggi $12,11 \%$ pada ukuran serbuk biji pinang 20 mesh [9].

2. Maserasi kinetik-digesti biji pinang dengan pelarut aquadest didapatkan hasil terbaik pada $40^{\circ} \mathrm{C}$, lama proses ekstraksi 4 jam dengan yield 12,2\% dan tanin 424,99 mg GAE/gr [10].

3. Maserasi kinetik biji pinang dengan pelarut air, memvariasikan lamanya pemanasan dan ukuran serbuk mendapatkan hasil terbaik pada lama pemanasan 4 jam dan ukuran serbuk 80 mesh dengan kadar tanin sebesar $11,0022 \%$ [11].

4. Ekstraksi tanin dengan pelarut air dan etanol pada suhu $50-60^{\circ} \mathrm{C}$ menunjukkan kadar tanin lebih tinggi pada pelarut etanol dibandingkan pelarut air pada waktu ekstraksi 5 jam [4]

5. Ekstraksi biji pinang selama 3 hari dengan pelarut etanol 95\% didapatkan kandungan senyawa flavonoid $3,7 \%$, $\operatorname{tanin} 8,53 \%$ [12].
6. Aplikasi gelombang iradiasi ultrasonik untuk meningkatkan rendemen ekstrak dan efektifitas antioksidan pada kulit manggis, kombinasi terbaik pada amplitudo 65\%, waktu eksitasi 45 menit didapat rendemen $6,71 \%$ [13].

7. Ekstraksi daun jambu biji dengan bantuan iradiasi ultrasonik didapatkan total tanin tertinggi pada suhu $45^{\circ} \mathrm{C}$ waktu 20 menit yaitu sebesar 583,75 mg TAE/gr [14].

8. Kajian jenis pelarut dan lama ekstraksi bawang Dayak metode iradiasi bak ultrasonik, menggunakan pelarut etanol $96 \%$ dengan rasio 1:7 dan lama ekstraksi 30 menit didapat total fenol 240,62 mg GAE/gr [15].

\section{METODOLOGI}

\section{Bahan dan Alat}

Biji pinang yang digunakan adalah biji pinang jenis pinang wangi yang diperoleh dari Nagari Sikucua, Padang Pariaman. Pelarut etanol yang digunakan adalah pelarut $96 \%$ yang diencerkan menjadi konsentrasi $35 \%, 50 \%, 65 \%$ dan $80 \%$. Reagen Folin Denish, $\mathrm{Na}_{2} \mathrm{CO}_{3}$ jenuh, Asam Tanat, Aquadest. Alat yang digunakan terdiri dari blender laboratorium, ayakan ukuran 20, 40 dan 70 mesh, oven, beaker gelas, gelas ukur, labu takar, kertas saring whatmann, ultrasonik bath (elmasonic), waterbath, vacum buchner, rotary evaporator, spektrofotometer UV-Vis.

\section{Preparasi Bahan}

Biji pinang dihancurkan dan dihaluskan menjadi serbuk menggunakan laboratory blender lalu di oven pada suhu $105^{\circ} \mathrm{C}$ selama kurang lebih 3-4 jam. Dilanjutkan tahap proses penghalusan tahap kedua dengan menggunakan laboratory blender selama 40 detik, diaduk, dan dihaluskan lagi 40 detik. Waktu penghalusan ini diberikan seragam sebagai parameter fix hasil dari pengujian awal untuk mendapatkan ukuran serbuk yang diinginkan. Hasilnya kemudian disaring pada sieve 20, 40 dan 70 mesh. Biji pinang halus lalu disimpan dalam plastik vacuum untuk menjaga kualitasnya agar tidak rusak terkontaminasi mikroba seperti pada gambar 4 . 


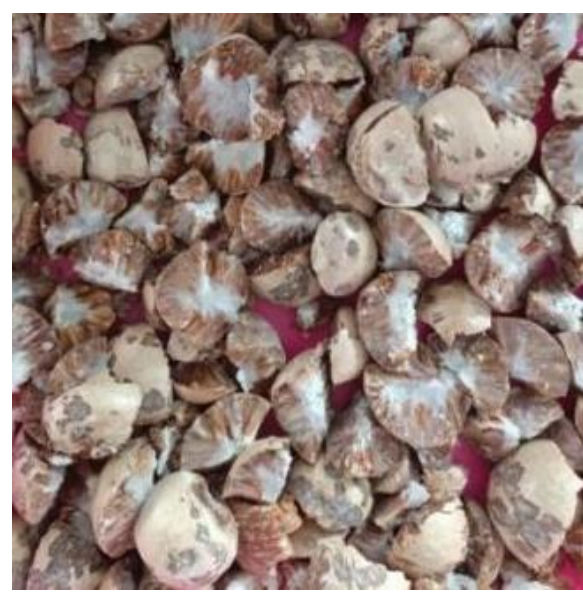

Gambar 3. Pecahan Biji Pinang Segar

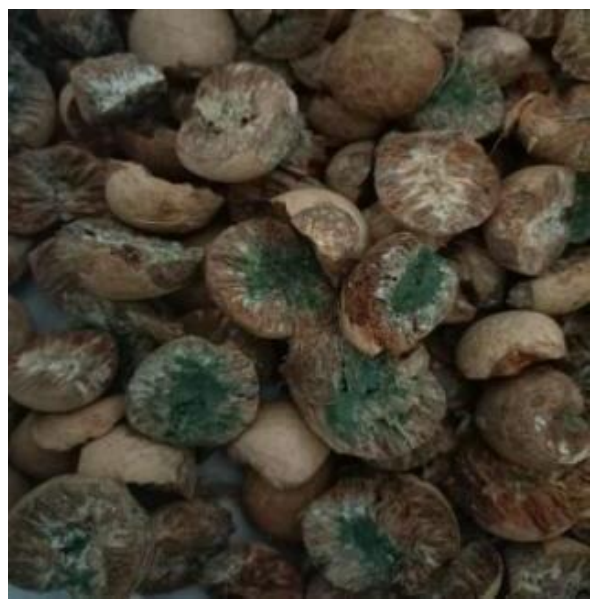

Gambar 4. Pecahan Biji Pinang Rusak Terkontaminasi Mikroba

\section{Preparasi Alat}

Alat iradiasi ultrasonik bath tipe Elmasonic S $30 \mathrm{H}$ dengan frekuensi 50/60 kHz, daya 280 Watt dioperasikan pada kondisi frekuensi tetap. Temperatur operasi dapat diatur pada $45^{\circ} \mathrm{C}$. Waterbath diatur pada temperatur $45^{\circ} \mathrm{C}$ diisi air lalu diatur gerakan getarnya (shaking) pada level paling kuat. Dalam penelitian sebelumnya didapatkan bahwa temperatur optimum ekstraksi dengan bantuan gelombang iradiasi ultrasonik adalah $45^{\circ} \mathrm{C}$. [11]

\section{Ekstrasi dengan Pra-Perlakuan iradiasi ultrasonik}

Biji pinang sebanyak $20 \mathrm{~g}$ dalam variasi 20 mesh, 40 mesh dan 70 mesh ditambahkan pada etanol 35\%, 50\%, $65 \%$ dan $80 \%$ dengan perbandingan 1:10 (b/v). Ditempatkan dalam beaker gelas ukuran $250 \mathrm{ml}$ lalu ditutup aluminium foil. Sampel ini dimasukan pada alat elmasonic yang diatur temperatur pada $45^{\circ} \mathrm{C}$ dan lama iradiasi 15 menit.

Waktu iradiasi ultrasonik diatur untuk 15 menit untuk menjaga temperatur air tidak naik melebihi $45^{\circ} \mathrm{C}$ selama proses berlangsung. Kenaikan temperatur dapat terjadi selama iradiasi disebabkan oleh eksitasi gelombang iradiasi ultrasonik yang terlalu lama. Selama proses iradiasi ultrasonik berlangsung beaker gelas ditutup rapat dengan aluminium foil untuk menghindari losses pelarut. Variasi tidak dilakukan lebih dari $45^{\circ} \mathrm{C}$ untuk menghindari kerusakan kandungan tanin.

Setelah selesai eksitasi gelombang iradiasi ultrasonik, proses maserasi dilanjutkan dengan menempatkan sampel di waterbath yang telah di set temperatur $45^{\circ} \mathrm{C}$ dan diberikan gerakan shaking cepat sampai total waktu dari awal pra-perlakuan sejak di Elmasonic dilanjutkan sampai mencapai waktu proses total 4 jam. Sampel yang telah dimaserasi di endapkan selama 30 menit sampai mencapai kestabilan pengendapan, dan kemudian disaring dengan menggunakan corong Buchner dan pompa vakum untuk memisahkan Rafinat dan ekstrak. Ekstrak kemudian dipekatkan menggunakan rotary evaporator pada kondisi operasi putaran $35 \mathrm{rpm}$, Temperatur heating bath $53^{\circ} \mathrm{C}$ dan temperatur chiller $11^{\circ} \mathrm{C}$ dengan tekanan vakum $201 \mathrm{mBar}$.

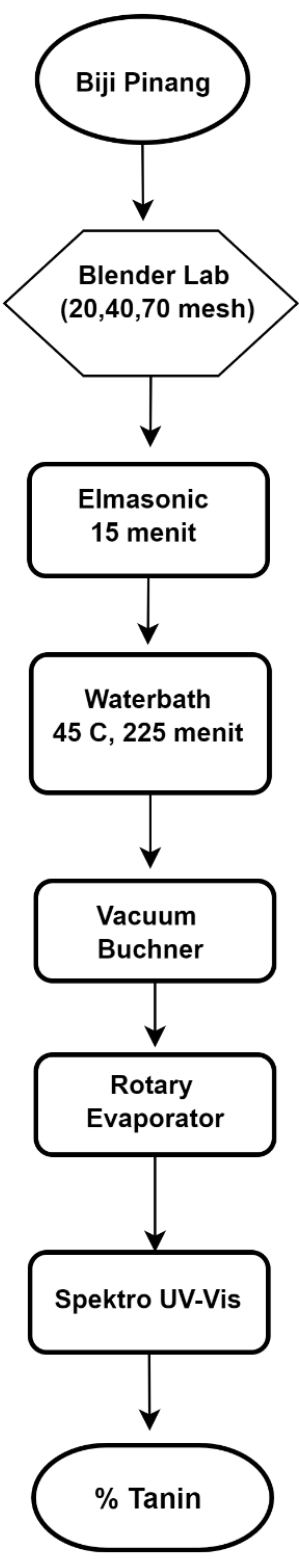

Gambar 5. Bagan Alat Proses Maserasi Pra-Perlakuan iradiasi ultrasonik 


\section{Uji Tanin}

Sampel dipipet 1,0 mL kemudian dimasukkan ke dalam labu takar $100 \mathrm{~mL}$ yang telah berisi aquadest. Selanjutnya diambil sampel sebanyak $5 \mathrm{~mL}$ dari pengenceran pertama untuk diencerkan kembali di labu takar $50 \mathrm{~mL}$. Kemudian diambil sampel $1 \mathrm{~mL}$ dari labu pengenceran kedua lalu ditambahkan $0,5 \mathrm{~mL}$ pereaksi Folin Denis dan 1,0 mL larutan $\mathrm{NaCO}_{3}$ jenuh. Dicampur dengan baik menggunakan vortex dan didiamkan selama 1 jam kemudian serapannya dibaca pada panjang gelombang maksimum.

Sebagai larutan standar dibuat larutan asam tanat dengan variasi konsentrasi dari 0 hingga $0,012 \mathrm{mg} / \mathrm{mL}$. Selanjutnya hasil bacaan absorbansi dimasukkan ke persamaan regresi dari deret standar asam tanath yang ada di Spektrofotometer UV-Vis.

Tabel 1. Absorbansi Deret Standar Asam Tanat

\begin{tabular}{cc}
\hline Konsentrasi $(\mathbf{m g} / \mathbf{m l})$ & Absorbansi \\
\hline 0,000 & 0,000 \\
0,004 & 0,282 \\
0,006 & 0,405 \\
0,008 & 0,581 \\
0,010 & 0,690 \\
0,012 & 0,855 \\
\hline
\end{tabular}

Persamaan regresi deret standar asam tanat mengikuti grafik dibawah ini didapatkan $\mathrm{y}=70,88449 \mathrm{x}-0,00381$.

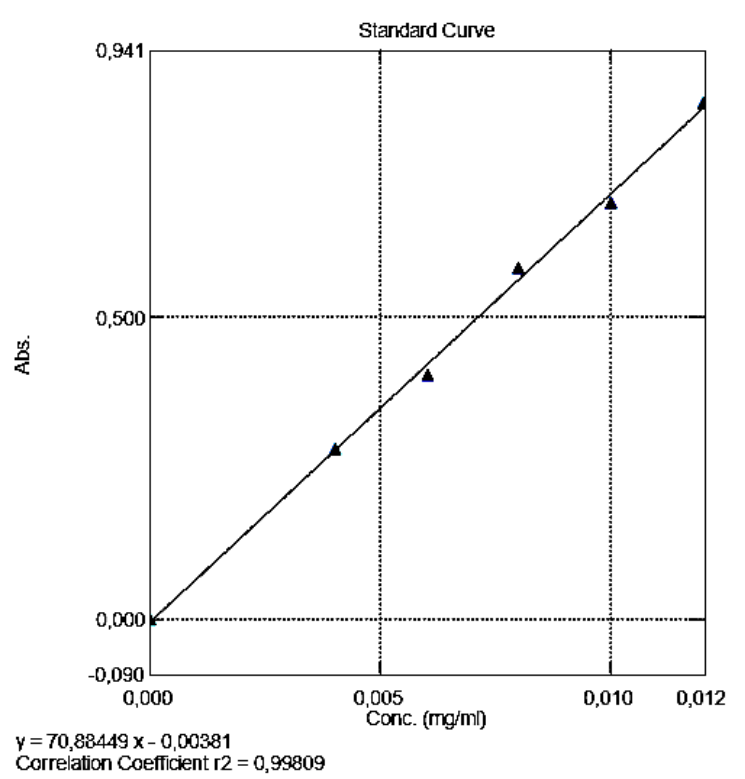

Gambar 6. Persamaan Regresi Deret Standar Asam Tanat

\section{HASIL DAN PEMBAHASAN}

\section{Konsentrasi pelarut}

Ditinjau dari kepolaran pelarut, kepolaran mempengaruhi kemampuan pelarut dalam menarik zat terlarut atau solut. Didapatkan bahwa konsentrasi pelarut yang semakin tinggi mampu menaikkan kadar tanin yang didapat. Hal ini sesuai dengan hasil penelitian dari Cahyanto [12], yang menjelaskan bahwa etanol konsentrasi tinggi memiliki sifat kepolaran relatif dimana senyawa tanin lebih mudah melarut ke etanol konsentrasi tinggi dibandingkan flavonoid.

Tabel 2. Perbandingan Konsentrasi Pelarut dan Ukuran Bahan Terhadap Kadar Tanin

\begin{tabular}{ccc}
\hline $\begin{array}{c}\text { Ukuran Bahan } \\
(\text { Mesh })\end{array}$ & $\begin{array}{c}\text { Pelarut } \\
(\boldsymbol{\%})\end{array}$ & Tanin (\%) \\
\hline 20 & 35 & 9,55 \\
& 50 & 9,02 \\
& 65 & 9,76 \\
& 80 & 10,04 \\
\hline 40 & 35 & 9,38 \\
& 50 & 9,66 \\
& 65 & 10,24 \\
& 80 & 11,10 \\
\hline 70 & 35 & 9,83 \\
& 50 & 9,42 \\
& 65 & 9,95 \\
& 80 & 10,17 \\
\hline
\end{tabular}

Gelombang iradiasi ultrasonik melewati partikel bahan sehingga bahan menjadi terekspansi dan terkompresi. Tekanan mekanik pada sel ini menyebabkan terbentuknya rongga atau kerusakan pada sel bahan yang akan memudahkan solut kontak dengan solvent dan meningkatkan laju difusi solut ke pelarut keseluruhan. Hasil uji spektro UV-Vis pada tabel 2 menunjukkan bahwa konsentrasi pelarut memberikan pengaruh positif terhadap kenaikan persentase tanin yang didapat dalam semua variasi mesh yang ada.

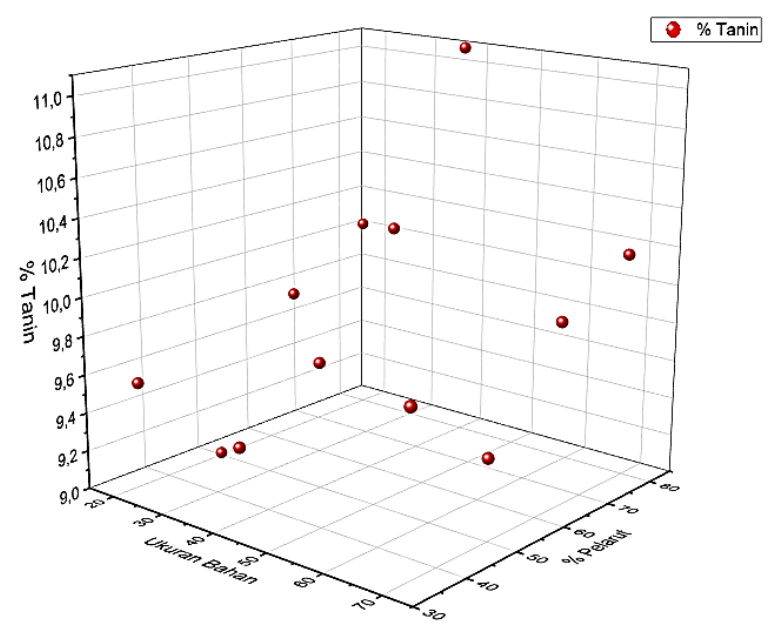

Gambar 7. Pengaruh Konsentrasi Pelarut Dan Ukuran Bahan terhadap Kadar Tanin

Selama proses iradiasi ultrasonik berlangsung pelarut (etanol) mengalami kavitasi akustik, yaitu pecahnya 
gelembung karena adanya pemanasan lokal. Letupanletupan gelembung kecil yang bergerak cepat mampu mengangkat serbuk biji pinang ke arah permukaan larutan. Hal ini dapat diamati selama proses iradiasi ultrasonik berlangsung dan sesaat setelah proses iradiasi ultrasonik dihentikan. Ketika larutan mengalami regangan, gelombang akan mampu memecah ikatan molekul antar larutan selanjutnya gas-gas yang terbentuk akan terperangkap saat larutan mengalami rapatan. Kavitasi akustik ini dipengaruhi oleh fisik dari medium perambatannya [16].

Efek kavitasi akustik dari iradiasi gelombang ultrasonik berperan membantu proses pencampuran dan deaglomerasi. Semakin tinggi konsentrasi etanol, kavitasi yang terjadi semakin banyak. Hal ini yang menyebabkan konsentrasi tanin meningkat dari setiap kenaikan konsentrasi pelarut yang diberikan. Energi dari iradiasi ultrasonik mempercepat proses homogenisasi sehingga kontak pelarut dan bahan sangat baik. Proses difusi tanin ke pelarut terbantu oleh proses mekanis ini. Kepolaran relatif dari etanol konsentrasi tinggi membuat tanin mudah larut sehingga kadar tanin tertinggi selalu didapat pada etanol konsentrasi $80 \%$.

\section{Ukuran Serbuk Biji Pinang}

Dalam interaksinya dengan serbuk biji pinang, rapatan dan rengangan yang terjadi pada pelarut selama iradiasi gelombang ultrasonik menghasilkan tekanan mekanik yang menyebabkan terjadinya perbesaran pori padatan serbuk biji pinang. Ukuran partikel bahan yang kecil memiliki luas permukaan efektif bahan yang lebih besar. Luas kontak yang besar akan memperbesar laju difusi. Ukuran partikel yang lebih kecil akan memperluas bidang interfacial antara fasa padat dan fasa cair, sehingga komponen bioaktif yang terkandung didalam fasa padat akan terekstrak lebih cepat $[17,18]$.

Penelitian yang dilakukan ini didapatkan bahwa kadar tanin yang didapat pada serbuk ukuran 40 mesh lebih tinggi dibandingkan ukuran 20 mesh dalam semua variasi konsentrasi etanol yang diberikan. Namun pada serbuk ukuran 70 mesh menunjukkan hal sebaliknya. Kadar tanin yang didapat lebih kecil dibandingkan serbuk ukuran 40 mesh dalam variasi pelarut kecuali pada etanol $35 \%$. Ditunjukkan dari hasil penelitian didapatkan bahwa bahan dengan ukuran 70 mesh hasil ekstraksi taninnya $10,17 \%$, hasil ini lebih rendah dibandingkan bahan ukuran 40 mesh yaitu $11,10 \%$.

Semakin halus partikel menyebabkan kerapatan antar partikel padatan jadi semakin besar atau bisa dikatakan jarak antara padatan semakin kecil. Kavitasi akustik yang terjadi selama iradiasi ultrasonik pada dasarnya membantu dalam deaglomerasi padatan ini. Akan tetapi belum terlihat maksimal pada ukuran serbuk 70 mesh. Kerapatan bisa memberikan hambatan lebih bagi gelombang ultrasonik untuk merambat melalui bahan tersebut. Yulian [5], menuliskan bahwa pada medium padat elastis homogen, kecepatan P-waves berbanding terbalik dengan kerapatan bahan. Semakin rapat bahan maka cepat rambat akan menurun.
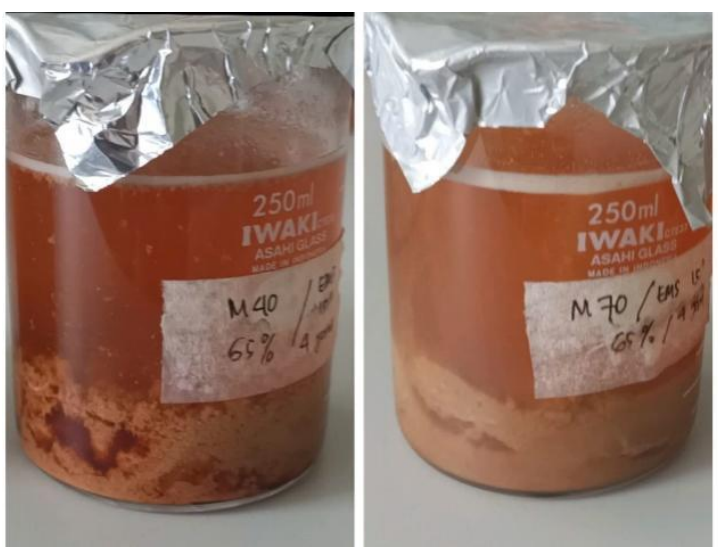

Gambar 8. Hasil Ekstraksi iradiasi ultrasonik Pada Serbuk Ukuran 40 mesh (a) dan 70 mesh (b)

Secara keseluruhan proses maserasi dengan iradiasi ultrasonik memberikan waktu proses lebih cepat dan kadar tanin yang lebih tinggi dibandingkan pada proses maserasi kinetik biasa. Dilihat dari penelitian sebelumnya yang dilakukan oleh Cahyanto [12], menggunakan pelarut etanol 95\% selama 3 hari tanpa bantuan iradiasi ultrasonik mampu hasil kadar tanin $8,53 \%$.

\section{KESIMPULAN}

Iradiasi gelombang ultrasonik terbukti mampu meningkatkan kadar tanin yang didapat pada proses ekstraksi biji pinang. Konsentrasi pelarut memberikan pengaruh nyata dalam peningkatan kadar tanin yang didapat.Ukuran serbuk dalam maserasi dengan praperlakuan iradiasi ultrasonik akan mempengaruhi laju ekstraksi. Serbuk yang sangat halus akan menghambat perambatan gelombang ultrasonik sehingga memberikan dampak kurangnya tekanan mekanik ke serbuk biji pinang. Maserasi pra-perlakuan iradiasi ultrasonik pada biji pinang 40 mesh dengan pelarut $80 \%$ menghasilkan tanin tertinggi sebesar $11,10 \%$.

\section{ACKNOWLEDGEMENT}

Penulis berterimakasih kepada Politeknik ATI Padang yang telah mendanai penelitian ini melalui Unit Penelitian dan Pengabdian Masyarakat Politeknik ATI Padang. Penelitian ini juga didukung oleh Laboratorium Integrasi, Laboratorium Operasi Teknik Kimia dan Laboratorium Pangan Politeknik ATI Padang. 


\section{DAFTAR PUSTAKA}

[1] C. S. Muir and R. Kirk. "Betel, Tobacco, and Cancer of The Mouth". British Journal of Cancer, Vo. Xiv (4), 1960, Pp. 597-608, Doi:10.1038/Bjc. 1960.65

[2] T. J. Mason and J. P. Lorimer. "Applied Sonochemistry: Uses of Power Ultrasound in Chemistry and Processing". Weinheim:Wiley-Vch Verlag Gmbh \& Co, 2002, Pp.43

[3] J. D. N. Cheeke. Fundamentals and Applications of Iradiasi Ultrasonik Waves $2^{\text {nd }}$ Ed. Boca Raton: $\mathrm{Crc}$ Press, 2012, Pp. 1-15.

[4] T. Sulastri. "Analisis Kadar Tanin Ekstrak Air dan Ekstrak Etanol pada Biji Pinang Sirih (Areca Catechu, L)”. Jurnal Chemica, Vol 10, 2009, Hal. 59-63

[5] A. E. Yulian. "Analisis Kerapatan Beton Dengan Menggunakan Cepat Rambat Dan Transmission Time Pada Alat UPV (Iradiasi Ultrasonik Pulse Velocity." Skripsi, Universitas Brawijaya, Malang, 2018.

[6] A. M. Bhandare., A. D. Kshirsagar., N. S. Vyawahare., A. A. Hadambar and V. S. Thorve. "Potential Analgesic, Amti-Inflamantory and Antioxidant Activities of Hydroalcoholic Extract Of Areca Catechu L. Nut". Food And Chemical Toxicology, Vol 4, 2010, Pp. 3412-3417. Doi:10.1016/j.Fct.2010.09.013.

[7] M. Silalahi. "Manfaat Dan Toksitas Pinang (Areca Catechu) Dalam Kesehatan Manusia". Bina Generasi: Jurnal Kesehatan, Vol 2 (11), 2020, Hal. 26-31

[8] K. Rathod., M. Shivaprasad and Rajshekhar. "Characterization and Extraction of Tanin From Areca Nut Waste and Using it as Rust Deactivator", International Journal of Science, Engineering and Technology, Vol 3(2), 2015, Pp. 366-372, Issn 2348-4098

[9] D. A. Anggorowati., H. Setyawati dan A. Artiyani. "Isolasi Tanin dari Limbah Biji Buah Pinang dengan Proses Ekstraksi-Destilasi”. Spectra, Vol Ix (18), Juli 2011, Hal. 49-57.

[10] N. L. Rahmah., B. S. D. Dewanti dan F. Azizah. "Combination of Kinetik Maceration Digestion in The Extraction of Areca Seeds (Areca Catechu L.)", AFSSAAE Advance In Food Science, Sustainable Agriculture and Agroindustrial Engineering, Vol 1(2), 2018, Hal.27-33, Doi.Org/10.21776/Ub.Afssaae.2018.001.02.4

[11] Karina., Y. Indrayani dan M. Dirhamsyah. "Kadar Tanin Biji Pinang (Areca Catechu L) Berdasarkan Lama Pemanasan dan Ukuran
Serbuk. Jurnal Hutan Lestari, Vol 4(1), 2016, Hal. 119-127

[12] A. H. Cahyanto. "Aktivitas Ekstrak Etanol Biji Pinang ”. Majalah Biam, Vol 14 (2), 2018, Hal. 70-73, Http://Dx.Doi.Org/10.29360/Mb.v14i2.410.

[13] M. Sholihah., U. Ahmad dan I. W. Budiastra. "Aplikasi Gelombang Ultrasonik Untuk Meningkatkan Rendeman Ekstrak dan Efektifitas Antioksidan dari Kulit Manggis". Jurnal Keteknikan Pertanian (JTEP), Vol 5 (2), 2017, Hal. 161-168

[14] S. Sekarsari., I. W. R. Widarta dan A. A. G. N. A. Jambe. "Pengaruh Suhu dan Waktu Ekstraksi dengan Gelombang Ultrasonik terhadap Aktivitas Antioksidan Ekstrak Daun Jambu Biji (Psidium Guajava L". Jurnal Ilmu dan Teknologi Pangan, Vol 8 (3), September 2019, Hal. 267-277, Doi:10.24843/Itepa.2019.v08.i03.p05

[15] N. C. R. Yuswi. "Ekstraksi Antioksidan Bawang Dayak (Eleutherine Palmifolia) dengan Metode Ultrasonic Bath (Kajian Jenis Pelarut dan Lama Ekstraksi”. Jurnal Pangan dan Agroindustri, Januari 2017, Vol 5 (1), Hal. 71-79.

[16] A. Lancia., D. Musmarra and M. Prisciandaro. Kirk-Othmer Encyclopedia of Chemical Technology 4th Ed. New York: J. Wiley \& Sons, 1998, Vol. 26, Pp. 517-541

[17] Erminawati dan R. Naufalin. "Sifat Fisikokimia dan Aktifitas Antioksidan Sarang Semut (Myrmecodia Pendans) Sebagai Pengawet Alami Pangan", Patpi, Vol 1,2013, Hal. 1-15

[18] L. K. D. Indriyani., L. P. Wrasiati dan L. Suhendra. "Kandungan Senyawa Bioaktif Teh Herbal Daun Kenikir (Cosmos Caudatus Kunth) pada Perlakuan Suhu Pengeringan dan Ukuran Partikel". Jurnal Rekayasa Dan Manajemen Agroindustri, Vol 9 (1), Maret 2021, Hal. 109-118. Issn: 2503-488X. 